\title{
OPTIMALISASI PERAN GURU DALAM MENDIDIK KARAKTER PESERTA DIDIK MELALUI MEDIA TEMBANG MACAPAT PANGKUR PUPUH 2 SERAT WEDHATAMA
}

\author{
Sarafuddin, Winarto \\ asarafuddinmi11@gmail.com \\ binbarog19@gmail.com
}

Program Studi Pendidikan Guru Sekolah Dasar Universitas Slamet Riyadi Surakarta, 57126, Indonesia

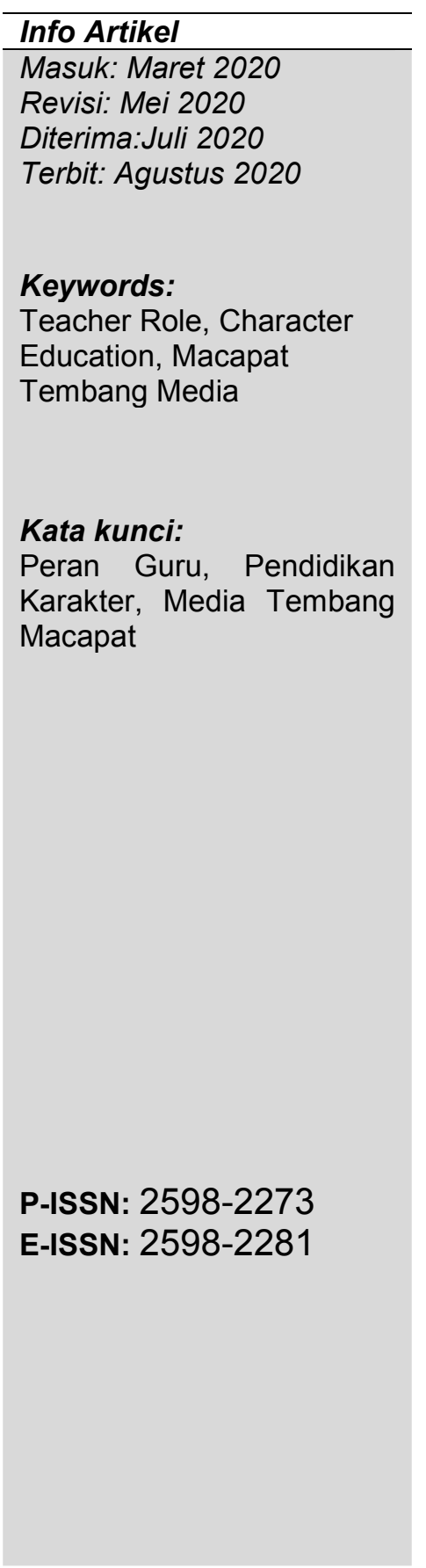

\begin{abstract}
This community service activity aims to optimize the role of the teacher in educating the character of students through the media of macapat pangkur pupu 2 white fiber in SDN 02 Papahan Tasikmadu Karanganyar. The role of the teacher in school is very influential on the progress and development of the character of students to recognize and love the arts and culture of the region. Character education can also foster a positive personality in students to appreciate the local wisdom of their area. So far, sometimes teachers in schools only carry out teaching obligations with the demands of achieving learning material completeness. This means that teachers in schools are not optimally utilizing learning media, especially art-based media to educate students' characters. This condition was obtained based on the results of an initial survey conducted at SDN 02 Papahan Tasikmadu Karanganyar.

This dedication was carried out at SDN 02 Papahan Tasikmadu Karanganyar. The method of implementing the service includes: (1) the method of approach taken from the survey, and licensing stages, and (2) the method of program implementation, including the preliminary stage, the socialization and audience stage, the implementation and collaboration stage, and the evaluation stage. The expected output target is the SDN 02 Papahan Tasikmadu Karanganyar teachers who take part in this activity have a high sensitivity and concern for the character education of students so that they can reap good achievements. Besides that, scientific articles can also be arranged to be published in national journals with ISSN. This activity was attended by 20 participants from teachers and students of SDN 02 Papahan Tasikmadu Karanganyar.

It is hoped that this activity will be able to strengthen teachers 'understanding of the importance of mentoring in instilling students' character. This condition cannot be denied that if students are brought closer and taught about local wisdom such as the song of macapat pangkur canto 2
\end{abstract}


Wedhatama fiber, then in themselves they will grow good character that is love for the arts and culture of the region.

\begin{abstract}
Abstrak
Kegiatan Pengabdian masyarakat ini bertujuan untuk mengoptimalkan peran guru dalam mendidik karakter peserta didik melalui media tembang macapat pangkur pupu 2 serat wedhatama di SDN 02 Papahan Tasikmadu Karanganyar. Peran guru di sekolah sangat berpengaruh pada kemajuan dan perkembangan karakter peserta didik untuk mengenali dan mencintai seni dan budaya daerahnya. Pendidikan karakter juga dapat menumbuhkan kepribadian positif pada peserta didik untuk menghargai kearifan lokal daerahnya. Selama ini kadang-kadang guru di sekolah hanya sekedar melaksanakan kewajiban mengajar dengan tuntutan ketercapai ketuntasan materi pembelajaran. Artinya bahwa guru di sekolah kurang maksimal dalam memanfaatkan media pembelajaran terutama media berbasis seni untuk mendidik karakter peserta didik. Kondisi ini diperoleh berdasarkan hasil survei awal yang dilakukan di SDN 02 Papahan Tasikmadu Karanganyar.

Pengabdian ini dilakukan di SDN 02 Papahan Tasikmadu Karanganyar. Metode pelaksanaan pengabdian meliputi: (1) metode pendekatan yang dilakukan mulai tahap survei, dan perijinan, dan (2) metode pelaksanaan program, meliputi tahap pendahuluan, tahap sosialisasi dan audiensi, tahap pelaksanaan dan kolaborasi, dan tahap evaluasi. Target luaran yang diharapkan adalah guru-guru SDN 02 Papahan Tasikmadu Karanganyar yang mengikuti kegiatan ini memiliki kepekaan dan kepedulian yang tinggi terhadap pendidikan karakter peserta didik sehingga dapat menuai prestasi yang baik. Selain itu juga dapat tersusun artikel ilmiah untuk dimuat dalam jurnal nasional ber ISSN. Kegiatan ini diikuti oleh 20 peserta dari guru dan peserta didik SDN 02 Papahan Tasikmadu Karanganyar.

Diharapkan dengan adanya kegiatan ini akan dapat memberikan penguatan pemahaman pada guru-guru tentang betapa pentingnya pendampingan dalam menanamkan karakter peserta didik. Kondisi tersebut tidak bisa dipungkiri bahwa apabila peserta didik didekatkan dan diajarkan tentang kearifan lokal seperti tembang macapat pangkur pupuh 2 serat wedhatama, maka pada diri mereka akan tumbuh karakter baik yaitu kecintaan terhadap seni dan budaya daerahnya.
\end{abstract}




\section{PENDAHULUAN}

Tembang macapat adalah sebuah bentuk tembang (menyanyi) jawa, yang menggunakan laras musik jawa pelog/slendro (pentatonis/diatonis) yang berpegang pada guru lagu dan guru wilangan. Guru Lagu adalah ;tibaning lagu swara ing pungkasaning gatra/gendhing. Guru wilangan adalah; jumlahing lagu/swara ing pungkasaning gatra. Berpijak dari keterangan di atas dapat disimpulkan bahwa dalam tembang macapat ada sebuah tehnik dan aturan yang harus ditaati. Berdasarkan penjabaran di atas, dirasa sangat perlu dan penting untuk pendidikan Sekolah Dasar tembang dimasukkan dalam mata pelajaran wajib, yang berpijak pada kearifan lokal dengan basis seni dan budaya kedaerahan, agar bisa memberikan pemahaman kepada anak Sekolah Dasar agar mengenal dan mampu mengimplementasikan yang sudah diajarkan gurunya.

Pendidikan dasar merupakan sebuah kunci utama untuk membentuk kepribadian dan karakteristik manusia. Berhasil atau tidak, berkwalitas atau rusak, tergantung metode pada sistem penyampaian pada pendidiknya.Guru Sekolah Dasar mempunyai peran penting terhadap pendidikan anak didiknya dengan penuh tanggung jawab besar dalam rangka mewujudkan embrio manusia yang berkualitas baik yang berdasarkan akhlak mulia, budi pekerti, beragama, dengan penuh jiwa Pancasila. Kemampuan paralel seorang guru dalam mengajar jarang sekali dimiliki, kebanyakan akan lebih menitik beratkan pada skill kemampuan dibidangnya masingmasing, tembang, tari, dan teater adalah bidang seni yang sangat langka, untuk bisa dikuasai. Pendidikan dan pelatihan seni sangat dirasa penting dan perlu untuk anakanak Sekolah Dasar, karena pendidikan dan pelatihan seni, akan memperhalus akhlak dan budi pekerti manusia.

Melihat kenyataan yang berkembang dalam masyarakat akademisi yang dalam skala mayoritas tidak memahami tentang tembang dan nilai-nilai yang terkandung didalamnya, maka sangat perlu diberikan pendidikan dan pelatihan tembang berikut dengan penjabaran filosofi dan nilai-nilai positif yang bersifat mengajarkan kebaikan atau mengajak manusia untuk selalu berhati-hati dan cenderung berbuat kebaikan. Tembang Macapat Pangkur, merupakan salah satu pilihan yang kami anggap tepat dari 11 tembang macapat yang ada yaitu: 1. Mijil, 2. Kinanthi, 3. Sinom, 4. Asmarandana, 5. Dhandhang Gula, 6. Maskumambang, 7. Durma, 8. Pangkur, 9. Gambuh, 10. Megatruh, 11.Pocung. Alasan kami yang paling mendasar memilih tembang macapat Pangkur untuk proses pelatihan dan pembelajaran adalah, karena tembang pangkur mempunyai sifat madah dipelajari, dan karakternya sangat mendidik.

\section{METODE PELAKSANAAN}

Metode pendekatan yang dilakukan mulai (1) tahap survei, perijinan, dan pemberian motivasi bagi guru yang akan mengikuti pelatihan (2) metode pelaksanaan program, meliputi tahap pendahuluan, tahap sosialisasi dan audiensi, tahap pelaksanaan, serta tahap evaluasi akhir. 
Tahap pendahuluan dilaksanakan dengan mempersiapkan surat ijin dengan pihak terkait, mempersiapkan tempat pelatihan, mempersiapkan materi, alat dan bahan. Tahap sosialisasi dan audiensi dilakukan dengan cara memberikan pelatihan penyusunan materi pembelajaran seni berbasis kearifan lokal berupa tembang macapat pangkur pupuh 2 serat wedhatama dengan cara mengumpulkan guru-guru dan peserta didik SD negeri 02 Papahan Tasikmadu Karanganyar, kemudian memberikan penjelasan kepada tentang pentingnya menanamkan pendidikan karakter kepada peserta didik melalui seni budaya lokal.

Tahap pelaksanaan kegiatan pelatihan dilakukan dengan memulai pelatihan penyusunan dan sosialisasi program dengan metode ceramah partisipatif, interaktif, dan dialogis. Melalui metode ini, peserta pelatihan dengan mudah dapat memahami dan mencerna yang kemudian diterapkan dalam menyusun materi pembelajaran mereka masing-masing. Di samping itu proses pelaksanaan pengabdian juga dilakukan dengan metode ceramah, tanya jawab, diskusi, dan praktek secara langsung oleh peserta.

Tahap evaluasi kegiatan dilakukan dengan cara mengevaluasi kegiatan pelatihan penyusunan materi pembelajaran seni berbasis kearifan lokal dalam bentuk tembang macapat pangkur, kemudian dianalisis kelebihan dan kekurangannya selama pelaksanaan kegiatan pengabdian masyarakat berlangsung.

\section{PEMBAHASAN}

Hasil yang dicapai dari kegiatan pengabdian masyarakat ini adalah meningkatnya kemampuan dan keterampilan guru SD Negeri 02 Papahan Tasikmadu dalam penyusunan materi pembelajaran seni yang berbasis kearifan lokal seperti tembang macapat Pangkur Pupuh 2 Serat Wedhatama. Kondisi ini terlihat berdasarkan hasil evaluasi dan simulasi pada pelatihan kegiatan pengabdian masyarakat yang telah dilaksanakan sehingga dapat diketahui bahwa para guru khususnya guru yang mengajar materi pembelajaran seni pemahamannya semakin meningkat. Indikatornya adalah semula peserta belum memahami dan terampil dalam menyusun dan mengajarkan materi pembelajaran seni tembang macapat Pangkur Pupuh 2 Serat Wedhatama, maka setelah mengikuti kegiatan pelatihan tersebut, kemampuan dan ketrampilan guru meningkat. Guru dapat mengerti dan memahami betapa pentingnya makna edukatif dari pembelajaran materi seni bersumber dari kearifan lokal karena dapat menumbuhkan karakter positif pada peserta didik berupa kecintaan mereka terhadap seni budaya daerahnya.

Kegiatan pelatihan ini direncanakan diikuti oleh 20 orang peserta, terdiri dari 12 orang guru dan 8 orang peserta didik. Artinya target yang direncanakan bahwa 
dari jumlah peserta yang mengikuti pelatihan diharapkan $75 \%$ peserta yang hadir yaitu 9 orang guru dan 5 orang peserta didik telah berubah pandangan mereka tentang pentingnya pembelajaran kearifan lokal berupa seni tembang macapat Pangkur Pupuh 2 Serat Wedhatama. Keadaan ini dirasa cukup berhasil mengingat SD negeri 02 Papahan merupakan sekolah dasar yang cukup maju dengan pengelola atau manajemen sekolah terdiri dari 1 orang kepala sekolah dan 15 orang guru kelas serta guru bidang studi.

Mengingat bahwa salah satu tugas guru adalah mendidik, karena mendidik merupakan salah satu pekerjaan yang tidak gampang atau tidak mudah sebab dalam mendidik seorang guru harus mampu menanamkan akhlak serta budi pekerti yang baik, sehingga bisa membentuk pribadi yang, jujur, dan bertanggungjawab. Melalui tembang Pangkur Pupuh 2 Serat Wedhatama tersebut di atas diharapkan dapat mempermudah guru dalam pembelajaran dan mendidik akhlak serta budi pekerti yang baik. Hal ini disebabkan bahwa di dalam tembang Pangkur Pupuh 2 Serat Wedhatama pada setiap gatranya telah mengandung nilai-nilai ajaran kehidupan yang sangat luhur dan baik. Dengan mempelajari tembang macapat Pangkur Pupuh 2 Serat Wedhatama yang mempuyai watak serta karakteristik seperti tersebut di atas, di harapkan mampu membangun spirit yang bisa membangkitkan jiwa keberanian dan kesetiakawanan dalam rangka mewujudkan kualitas sumber daya manusia yang profesional dan berkomitmen tinggi untuk selalu menjaga kebersamaan dan kegotong royongan dalam setiap interaksi manusia sebagai mahluk sosial.

Sangat diharapkan setelah kegiatan ini untuk tahun pelajaran berikutnya dapat dicantumkan dalam program kerja sekolah yang berisi kegiatan pelatihan terkait dengan penyusunan materi pembelajaran seni berbasis kearifan lokal. Selain itu juga dapat dilakukan pelatihan penyusunan nada dan notasi untuk berbagai macam tembang lainnya sehingga dapat mempermudah guru dalam membelajarkannya pada peserta didik yang saat ini menjadi salah satu kelemahan di SD negeri 02 Papahan. Rencana ini muncul berdasarkan masukan dari beberapa guru khususnya yang mengajar mata pelajaran seni dengan indikasi mereka mengalami kusilitan dalam menyampaikan pembelajaran terutama pada aspek nada dan notasi. Bila ke depan rencana ini terealisasi, maka pelaksana kegiatan membuat perencanaan yang 
lebih sistematis dengan mengarah pada praktek dan simulasi sehingga peserta memiliki pengetahuan yang lebih luas dan jelas.

Pelaksanaan kegiatan pengabdian masyarakat ini merupakan suatu rangkaian tahapan-tahapan kegiatan yang akan direncanakan sebagai kegiatan yang berkelanjutan. Adapun rencana tahapan berikutnya adalah mengadakan kegiatan workshop terkait dengan penyusunan materi pembelajaran seni berbasis kearifan lokal. Dalam hal ini lebih difokuskan pada pelatihan penyusunan nada dan notasi untuk berbagai macam tembang lainnya sehingga dapat mempermudah guru dalam membelajarkannya pada peserta didik yang saat ini menjadi salah satu kelemahan di SD negeri 02 Papahan. Kegiatan ini menjadi masalah yang urgent bagi guru berdasarkan masukan dari beberapa guru khususnya yang mengajar mata pelajaran seni dengan indikasi mereka mengalami kusulitan dalam menyampaikan pembelajaran terutama pada aspek nada dan notasi.

Bila dilihat dari potensi yang dimilik, SD negeri 02 Papahan merupakan lembaga formal milik pemerintah yang senantiasa sangat mudah untuk memasukkan unsur-unsur kearifan lokal dalam pembelajaran seni dan sangat dimungkinkan untuk diprogramkan dalam kurikulum muatan lokal. Melalui kurikulum muatan lokal tersebut, diharapkan dapat menjadi pedoman bagi guru seni dalam menyusun perangkat pembelajaran berbasis kearifan lokal seperti seni tembang macapat. Apabila rencana ini ke depan dapat diwujudkan, maka tentunya akan terlihat mutu dan kualitas guru dan peserta didik semakin bertambah karena potensi yang dimilikinya dapat digali dan sekaligus dapat dipraktekkan dalam kegiatan pembelajaran. Di sisi lain, karakter peserta didik juga akan menjadi baik sebab pada diri mereka tumbuh kecintaan terhadap nilai-nilai tradisi dan budaya yang ada di daerahnya.

Berdasarkan pernyataan tersebut, maka tembang macapat sangat memungkinkan untuk diajarkan di tingkat pendidikan dasar karena dapat dijadikan sebagai sarana atau media pembelajaran pendidikan karakter. Sebuah kenyataan bahwa pada hakekat manusia hidup dan dilahirkan di dunia ini tidak hanya menjalani proses kehidupan tanpa tindakan apapun, akan tetapi banyak manusia yang tidak menyadari tentang makna hidupsejati sehingga dia lebih menikmati dan terlena pada keindahan dunia yang sebenarnya itu adalah kiasan hidup yang semu dan menipu 
manusia itu sendiri. Oleh karena itu, pendidikan karakter harus betul-betul menjadi prioritas utama dalam setiap bentuk pembelajaran lebih-lebih lebih pembelajaran seni berbasis kearifan lokal.

Sehubungan dengan keberlanjutan pelatihan penyusunan materi pembelajaran seni berbasis kearifan lokal yang difokuskan pada pelatihan penyusunan nada dan notasi untuk berbagai macam tembang, maka rencana tahapan berikutnya adalah melakukan workshop dan langsung praktek. Kegiatan tersebut diformulasi seperti itu, dengan tujuan agar guru dapat mengembangkan kompetensinya tidak hanya pada penyusunan perangkat pembelajaran saja tetapi lebih mengarah pada penyusunan bahan ajar yang berisi nada dan notasi tembang macapat. Melalui workshop dan pelatihan diharapkan guru akan lebih memahami dan menguasai terkait pentingnya membelajarkan seni berbasis kearifan lokal yang dapat menumbuhkan karakter positif pada peserta didiknya.

\section{PENUTUP}

Berdasarkan uraian uraian di atas, bahwa kegiatan pengabdian masyarakat bagi guru dan peserta didik SD negeri 02 Papahan Tasikmadu dapat disimpulkan sebagai berikut:

1. Pelatihan dan sosialisasi penyusunan materi pembelajaran seni berbasis kearifan lokal yang dilaksanakan dapat menigkatkan kemampuan dan pemahaman guru dalam menyusun materi pembelajaran dalam bentuk seni tembang macapat Pangkur Pupuh 2 Serat Wedhatama, sedangkan bagi peserta didik dapat tertanam karakter yang baik dan positif dalam bentuk kecintaan mereka terhadap tradisi dan seni budaya daerahnya.

2. Menemukan masalah mendasar terhadap belum optimalnya pemanfaatan kearifan lokal dalam bentuk seni tembang macapat Pangkur Pupuh 2 Serat Wedhatama sebagai kemasan materi pembelajaran khususnya mata pelajaran seni, dimana guru masih merasa kesulitan dalam menyusun nada dan notasinya.

\section{SARAN}

Berdasarkan kesimpulan di atas, dapat dikemukakan saran-saran sebagai berikut: 
1. Pelaksanaan kegiatan pelatihan dan sosialisasi penyusunan materi pembelajaran seni berbasis kearifan lokal ini diharapkan dapat dilanjutkan kepada pelatihan, workshop dan praktek penyusunan nada dan notasitembang macapat bagi guru SD negeri 02 Papahan.

2. Untuk meningkatkan pengetahuan dan keterampilan guru dalam menyusun materi pembelajaran seni berbasis kearifan lokalberbentuk seni tembang macapat, maka diharapkan adanya pelatihan, workshop dan praktek penyusunan nada dan notasisecara intensif agar guru lebih memahami tentang seni tembang macapat tersebut.

\section{DAFTAR PUSTAKA}

Barnawi \& M. Arifin, 2012.Strategi \& Kebijakan Pembelajaran Pendidikan Karakter. Yogyakarta: Ar-ruzz Media.

Furqon Hidayatullah, 2010. Pendidikan Karakter: Membangun Peradaban Bangsa. Surakarta: PT. Yuma Perkasa.

http://www.longlifeducation.com/2011/12/tembang-macapat pangkur.htm?m=1

http://megayumalia.blogspot.co.id/2015/08/bahasa-jawa-tembang-pangkurpangertene.html?m=1

Jamal Ma'mur Asnani, 2012. Buku Panduan Internalisasi: Pendidikan Karakter di Sekolah. Yogyakarta: Diva Press.

LPPM UNISRI.2013. Panduan Penelitian dan Pengabdian Pada Massyarakat. Surakarta. Universitas Slamet Riyadi.

Masnur Muslich, 2011. Pendidikan Karakter: Menjawab Tantangan Krisis Multidimensional. Jakarta: PT. Bumi Aksara.

M. Noor Rohinah, 2012. Mengembangkan Karakter Anak Secara Efektif di Sekolah dan di Rumah. Yogyakarta: PT. Pustaka Insan Madani.

Ida Zusnani, 2012. Manajemen Pendidikan Berbasis Karakter Bangsa. Jakarta: Tugu Publisher.

Setiyoko Fajar.2017, Kumpulan Tembang Macapat Lengkap dengan Penjelasan dan Contohnya. 